\title{
Espino Relucé, Gonzalo (2018). De ese hombre que dicen. Lima: Pakarina.
}

Se ha tornado lugar común comenzar una reflexión sobre poesía peruana señalando que la crítica literaria hegemónica no presta atención a determinadas producciones poéticas porque estas quebrantan la gramática y la sintaxis del análisis, tanto como subvierten los presupuestos ideológicos que organizan la retórica de la interpretación. Si la ceguera y el mutismo de cierta práctica crítica hacen imposible comprender la poesía que se escapa de los modelos estandarizados de escritura porque introducen la discontinuidad y la diferencia, resulta imperativo ejercer una crítica que sea operación estratégica de rescate y diálogo con aquellos poemarios que - pese a sus incuestionables valores estéticos y la sugerente propuesta ideológica - fueron olvidados por el discurso crítico hegemónico. En esa línea de trabajo damos cuenta, solo parcialmente, de algunos poemarios que aún esperan una lectura sistemática: Imágenes porque sí (1951) y La olvidada lección de cosas olvidadas (1966), de Julia Ferrer, seudónimo de Julia María del Solar Bardelli (1925-1995); Elogio de los navegantes (1966), de Juan Ojeda (1944-1974); El idiota del apocalipsis (1967), de Guillermo Chirinos Cúneo (1941-1999); El osario de los inocentes (1976), de Juan Cristóbal, seudónimo de José Pardo del Arco (1941); Aguardiente y otros cantares (1978), de Hildebrando Pérez Grande (1941); Trilogía del mar (1993), de Edgar Guzmán Jorquera (19352000); y Palabra fugitiva (1964), Objetos enajenados (1971) y Universo en el exilio (1984), de Yolanda Westphalen (1925-2011). Se trata de poemarios cuyo estudio podría enriquecer la percepción de las orientaciones poéticas en distintos momentos del proceso de la poesía peruana desde mediados del siglo XX hasta la década de los años noventa.

En este despliegue de la crítica como práctica de recuperación y diálogo con aquellos textos olvidados, es imperativo reflexionar sobre la producción poética de Gonzalo Espino Relucé (1956), esta recorre el convulsionado y sangriento marco histórico de la década de los años ochenta, y se proyecta 
hasta el horizonte actual, predominantemente líquido y auspicioso del ocaso de los metarrelatos. En los poemarios del siglo XX: Siete poemas de ficción real (1982), en realidad una plaqueta conformada por siete poemas, y Casa hacienda $(1991)^{1}$, Espino define dos orientaciones temáticas que serán una constante en su universo poético: la protesta social expresada en la huelga y la predilección por los elementos que componen el paisaje rural y urbano. El lenguaje que moviliza estos contenidos es uno en cuya estructura y sintaxis se perciben los giros orales del habla popular: el trujillanísimo "di”, los diminutivos, las palabras que van perdiendo progresivamente su constitución morfológica para hacerse expresiones gráficas orales: "ciudá”, "verdá", "usté", "pa"; así también, enunciados que hacen evidente el coro que habita tras la sintaxis versal: "Los cobriza arañando las cárceles / Y nuestras mujercitas teniendo su pecho con el nuestro / (con metrallas y patadas las montaban la cuadra)" (2016, p. 29).

Se trata de un lenguaje elaborado mediante una estrategia de descomposición metafórica que consiste en liberar el lenguaje poético de toda envoltura que lo encripte, lo oscurezca o hermetice. Con este método poético se logra modelar un lenguaje que produce efectos de transparencia, es decir, dar la sensación de que las palabras están engarzadas con las cosas y los hechos históricos (léase, por ejemplo, algunos de los títulos de los poemas: "Los compañeros de Cobriza", "Tomas de tierra", "Héroes del pueblo", "Trabajo honrado"). Queriéndolo o no, cuando el poeta asume esta estrategia de creación poética, muestra su sospecha de los velos retóricos que ocultan o alejan el lenguaje de los acontecimientos. Por ello, en el poema, la estrategia de descomposición opta por de-velar el lenguaje y la imagen para mostrar lo que se oculta, invisibiliza u oscurece; también, en algunos casos, el lenguaje escenifica el contacto y la fricción de la metáfora en proceso de des-montaje. El título de la plaqueta Siete poemas de ficción real expresa con propiedad esta fricción cuando se disponen en una misma secuencia semántica la idea de poema, ficción y lo real. Dicha opción oximorónica traza el contrato de lectura que se propone desde el título: que la lectura del poema fuese como si se asistiera al de-velamiento de las cosas y hechos ocultos (que en su mayoría son acontecimientos de reivindicación 
social). En el poema "Los compañeros de Cobriza", el lenguaje poético se ha descompuesto para develar el drama y la tragedia de un centenar de mineros asesinados a balazos por los "sinchis", grupo policial especializado en la lucha contrainsurgente.

Este desmontaje creativo produce y disemina términos que provienen de la esfera político-policial-represiva ("masacre", "metieron bala", "metrallas y patadas", "cárceles", "De sangre abaleado cayendo y con todo seguimos"), lo mismo que del campo económico y sindical ("compañeros mineros", "Los cobriza", "los sindicatos", "Todos, todos, nos repetimos — una y otra vezunidos, / ciertamente, unidos, no seremos vencidos"). Como se advierte, se trata de un universo poético cuyo mecanismo organizador es el conflicto. El poema "Héroes del pueblo" define la unidad semántica mediante una estructura acumulativa donde el encadenamiento versal hace de puente intensificador de una pugna entre oprimidos y opresores: “¿dónde luchadores y mártires, dónde? / ¿héroes del pueblo, dónde? Tendrán mil formas / ya palabra, ya consigna, ya volante, ya piedra, ya molotov / ya fusil, ya fuego /. Ya en fila. Overol o pala /. La curiosidad será todita nuestra. / Sobreviviremos a los secuestros, / matanzas, olvidos. Viviremos. Llanos. Lisos, maldita pesadilla en el lecho o falla en la cuenta bancaria. / Sindicato y huelga. Frente y subversión. Partido y lucha / Pueblo y guerra popular. / Y danzaremos en la cabeza de nuestro enemigo" (pp. 34-35). ¿Hacia dónde quiere llegar el planteamiento poético de descomposición? ¿Pretende, acaso, sacrificar la poesía en nombre de la propaganda? Es claro que el poeta busca redefinir la distancia entre el mundo y la palabra, acortar los límites que los separan para efectos de sentir la densidad del acontecimiento históricopolítico, el conflicto, la lucha. La inserción del tema político como centro organizador de sentido no le hace perder efectividad poética toda vez que el poema conserva, en algunos casos, el poder de sugerencia: "Los sinchis hieren aquello / Que nunca jamás se mata” (p. 29) y, en otros, el ritmo y la musicalidad: “Quizás compañero, a sobresaltos encarcelen / las ilusiones, quizá, camarada verás cómo / el invisible aroma de las flores de la coca / el rojo rojo de geranios acogen nuestras manos / y las retamas no teman más las pisadas perversas" (p. 32). 
Este acercamiento entre el mundo y la palabra, esta inserción del tema político como centro organizador de sentido, se encuentra también en Casa hacienda (1991) compuesto de cuatro estancias con un total de veintidós poemas, algunos breves, otros extensos, y en su gran mayoría de títulos que apelan a nombres de referentes regionales; leemos, entre otros: "Juanita Chuque", "Negro Robles", “Artemio Zavala", "Petita Carril", “Joaquín Díaz Ahumada", "María Cachaca" y "Primero de mayo". El paso de los años (nueve entre la plaqueta y el poemario) no ha modificado la estructura de significación del poema: el conflicto, la lucha; tampoco ha logrado eliminar la palabra del poeta como vehículo de anhelos sociales insatisfechos. Los títulos de los poemas aluden a personajes de la historia local; de hecho, en el pórtico del poemario se lee un fragmento del testimonio del líder sindical Joaquín Díaz Ahumada sobre el nacimiento del sindicato de trabajadores en el valle de Chicama. Así, bajo las faldas del "Cerro Mirador", los matorrales que rodean la "Casa hacienda", y la "caña" que se extiende como sabana verdosa adormecida por el río que le da su nombre al valle "Chicama", los versos de Casa hacienda diseminan el color y el olor del paisaje con "girasoles", "geranios", "sauces", "naranjos", "paltos", "ciruelos", "nísperos" y "yerbabuena"; poemario multicolor, pero no en un ejercicio de derroche plástico o cromático. No en una serie de trazos de naturaleza muerta. Menos, como una muestra del horror vacui. Sino como elementos donde reposa y se prolonga la memoria.

El escenario poético se presenta de esta manera, pues en él se insertan, por una parte, los vivos-elementos del patrimonio familiar. La palabra poética se descompone y simplifica para destacar sonido a sonido la significación de sí misma: "Mi casa / hermanito / hermanita / chacra / siembra / girasol / parque. / Zafra / sin patrón. / No es nuestra. / Es nuestro / el sueño, / la vida" (pp. 62-63); $\mathrm{y}$, por otra parte, se introducen también la serie de problemas con los que deben de lidiar tanto los sujetos familiares (en los poemas se mencionan a los abuelos, la madre, los hermanos y los hijos), como los pobladores y trabajadores. Como se lee en el poema anterior cuya economía poética (por la escasez de palabras que la componen) logra expresar en su materialidad, la escasez o la carencia de 
la propiedad de la tierra: esta casa no es nuestra, solo son nuestros los sueños y la vida [y agregamos para rematar el verso, es suya también la mano de obra]. La alusión a sujetos sociales en condiciones de carencia se complementa con recuerdos cotidianos de la escuela, los juegos, los premios y los castigos, pero, sobre todo, con la presencia de los "cogollos del alma": personas muy significativas para el imaginario social y personal del poeta; una de ellas, "María Cachaca", quien en un día de paro y protesta, y frente a la caballería de policías que dispara contra los huelguistas, expresa con voz acerada: "no importa que no salgan los maridos. / Aquí las mujeres somos machas" (p. 75).

La estrategia de descomposición metafórica, si bien trata de presentar el lenguaje poético lo más libre de aditamentos retóricos, produce por otra parte, el efecto de desautomatización a través de la autoexperimentación del lenguaje con sus propios límites y protocolos de referencialidad, y, ciertamente, recupera también el ritmo del habla popular. El poema que le presta su título al poemario cierra el mismo poniendo énfasis en la condición de carencia de la propiedad de la tierra, el conflicto social y la protesta. El lenguaje poético en clave económica desliza el descontento por el impuesto ("sisa"), intuye la arquitectura de la represión ("calabozo") y asume el conflicto como irrenunciable modo de supervivencia: “Aquí, arriba, la casa calcula / nuestro corazón de zapote / caída la última sisa. / La peonada, cuenta intensa la dulzura / sorprende rieles pegados al carbón / puerta, calabozo y trapiche" (p. 91). Como se debe haber deducido, los poemas no proponen resoluciones de un conflicto, de hecho, ninguno posee una estructura organizada para celebrar la victoria; por ello, acaso es que se encuentran diseminados en múltiples versos, estrategias de protesta y resistencia.

La producción poética de Espino Relucé cierra la década de los años noventa con ese entendido de reflexividad poética. Tendrán que pasar once años para que la escritura de este poeta peruano visibilice la indagación por otra esfera que, ciertamente, se insinuaba en varios de los poemas anteriores, pero que recién se definirá con rotundidad a inicios del siglo XXI: el tópico del amor. Más allá de la toma de tierras, la huelga o las estrategias de sabotear la hegemonía del poder, 
esta vez el utillaje poético se despliega por las arenas del amor, el mar del amar, y el enfermar de amor; el título del poemario lo condensa expresivamente: Mal de amantes (2002).

Este poemario, compuesto de 27 poemas distribuidos en cuatro estancias, es el que inaugura el discurrir poético de Gonzalo Espino por los primeros años del siglo XXI. Una suerte de repliegue íntimo y personal tras la exaltación de la lucha y el programa de acción sindical de la década pasada. Una clave de lectura - que es al mismo tiempo huella de continuidad poética toda vez que desde sus inicios el poeta es cronista y oidor de las voces populares - la proporcionan los versos de un vals cincelado como poética del amor: "Este amor que calla, / este amor que grita / este amor, este amor / que tanto duele, su magia tiene" (p. 97). Efectivamente, en cada estancia donde figura la amante, preferentemente de aparición metonímica y sinecdóquica, esta se mantiene sin habla, y cuando los versos buscan simbolizar alguna huella de su voz o sus acciones, casi siempre estas se muestran bajo la regulación (¿u ocultamiento?) de la dicción del amante. No habla en el café. No susurra en la cama. No grita por teléfono. No la vemos enloquecer por la espera. Aunque el amante se refiera a ella como "hembra en celo" (p. 139) o diga que posee una "pausa de garza de perra de gata de puta" (p. 114) que abisma, o que el amante confiese también que se pierde sin su amor, ella es como una abstracción, un recuerdo sin nombre propio (o una presencia innombrable); por ello, y acaso para convencernos de que no lo es (y aunque así lo reafirme), el amante introduce el descontento de su amada, siempre tutelando su expresión y su certeza: "aunque hayan dicho que no te amo [...] es una falsa noticia [...] no les creas, créeme" (p. 113). El poema “Amor amor" ilustra este sentimiento del poeta-amante que devela su amor y oculta a su amada: "No hay necesidad de nombres, ni de acuerdos, me basta saber que existo / y es que, sucede, como te dije, te estoy amando, / estoy contigo, ¿lo sabes, verdad?” (p. 139, nuestras cursivas). En la mayor parte de los poemas que componen Mal de amantes, el amor figura como nostalgia que traza los márgenes de la cercanía y la distancia. Las calles, los cafés, los cuartos de hotel, las llamadas telefónicas y la complicidad evocan el sabor a pimienta de la piel de la amada; son escenarios donde la euforia del amor ha impregnado todo 
de recuerdos felices; las botellas de cerveza, las colillas de cigarro y el aserrín de los bares son escenarios de la soledad, los tragos amargos y los prolongados momentos disfóricos. De hecho, el poemario propone una lógica explicativa sobre la nostalgia del amor: el poeta-amante canta lo que ha perdido, el amor de la amante. Y así lo hará, aunque viva otra historia ¿de amor?, ¿con un mismo final? El poema "Dentrofuera" lo simboliza desde su paradójica estructura: "esta melodía sábado 20 en la proximidad de $t u \mathrm{voz}$ / la fatiga de mi actual compañera / en mis manos sudorosas” (p. 120, nuestras cursivas). ¿Por qué ama a una mujer en el presente, y piensa en otra que está en su pasado? ¿Se trata de un amante que ama a la mujer equivocada? ¿Por qué la nostalgia del amante oculta los motivos de su fracaso amoroso?

Algunas aproximaciones para estas interrogantes podemos hallarlas en varios de los poemas que componen Quinto (2013). De hecho, visto en perspectiva, la escritura poética de Gonzalo Espino dialoga consigo misma, abre sus propias preguntas y busca contestarlas poemario tras poemario. En ese sentido, el poemario al que hacemos alusión, y que se compone fundamentalmente de poemas breves, se puede leer como la continuidad de una meditación poética, una suerte de explicación continuada sobre aquel sujeto amoroso que se construyó en el poemario anterior, y que nos hace saber que ama el cuerpo equivocado. El poema "Malero", siempre en la pauta poética de la economía del lenguaje que procura el efecto de una imagen rotunda e imborrable, estampa categóricamente, a modo de confesión, la tipificación de su conducta y costumbre: "Siempre fui el más perverso de todos / malero feliz que confundió tu boca y me divertía de tu nariz. / Fue todo fatiga y ausencia definitiva" (p. 153, nuestras cursivas). En esa línea de meditación (intratextual) sobre la interacción con la o las (bien y mal) amada/s, en el poema "Fuera", el poeta-amante que ahora se presenta como sujeto poético reflexivo que realiza el examen de su vida sentimental explica el motivo de sus desencuentros amorosos: "Soy ese hombre que sus mujeres botan / cuando llega el hartazgo / o cuando el moche baja con los ojos / apagados. / Mis tribus de ciudad, de barrio, distantes. Fuera” (p. 161). Es imposible no atar cabos poéticos informativos (intratextuales) respecto al porqué los sujetos amorosos de Mal de 
amantes no continuaron su amor. Es imposible no buscar una explicación del porqué de aquel fracaso amoroso. Las palabras destacadas con cursivas insinúan alguna respuesta que diecisiete años más tarde, en el poemario: De ese hombre que dicen (2018), lo explicará el sujeto poético a manera de aceptación plena de su modo de vida amorosa: "Sería infiel si declaro siete divorcios y tres esposas, sería / digo, arriba está ella, abajo la morocha. / Vivo entre esos dos universos, entre tú y ella / o acaso alguien nos enseñó que / era malero amar a otra mujer o, a otro hombre" (p. 42).

De esta manera, la producción poética de Gonzalo Espino se hace meditación constante, toda vez que entre sus poemarios se pueden establecer relaciones intratextuales que ayudan a comprender mejor el sentido poético que proponen. Precisamente esta relación intratextual es la que permite establecer conexiones entre la totalidad de la producción poética desde la década de los años ochenta hasta la actualidad. De ese hombre que dicen (2018), tercer poemario del siglo XXI, resulta en tal sentido escenario donde se diseminan y actualizan los recursos expresivos que caracterizan la gramática y la retórica de la composición poética, así como resulta articulador de buena parte de los núcleos temáticos que acompañan a su autor desde hace treinta y siete años. En la solapa izquierda de este poemario se inserta la concepción que el poeta tiene sobre la poesía como: "Palabra que no teme decir las cosas tal como [...] ha tocado vivirlas, entre despojos o injusticias [...] esa palabra que se conmueve y expresa su disenso y protesta contra todo aquello que afecte a la condición humana" (nuestras cursivas).

Este es el programa de acción que la producción poética ha llevado en marcha desde la década de los ochenta hasta la actualidad. Se trata de una postura que va acompañada de una idea sobre el lenguaje poético como herramienta que comunica y expresa rotundamente los avatares de la experiencia vital, una experiencia que no se restringe al poeta y su universo personal, sino que abarca también a la experiencia de vida en sociedad. Se trata de una actitud de disenso poético por cuyo lenguaje se expresan los diversos problemas que acontecen en la realidad. Un lenguaje de vivencia, sobrevivencia y supervivencia. Uno que no teme descomponer el lenguaje poético para hacer de esa misma operación 
un modo de componer poesía. Uno que opta por la economía y simplificación del verso para lograr mayor efecto perceptivo de la imagen, para que esta no se desgaste en la proliferación de versos iterativos. Son en estos hechos donde se pone de manifiesto la política de su poesía y el modo cómo se hace poesía de la política y los sentimientos. Precisamente, la inserción del tema político dentro de la poesía es — valga la redundancia — una política de trabajo poético persistente a través de los años. Lo hemos visto en los poemas de la plaqueta que canta a favor de la huelga y la legitimidad de la toma de tierras y la resistencia frente a la represión; se ha presentado también a lo largo de los primeros poemarios en el límpido horizonte del valle o la verdosa sabana de la caña de azúcar en cuya desnudez expresiva se cifra la explotación, el abuso de poder y la carencia; sin duda, también se deja ver a través de insinuaciones sobre el malestar social que habita en las zonas urbanas y que atraviesa tanto a las personas agrupadas en los sindicatos, como a los amantes que evocan e invocan el disenso y la libertad.

El poema que cierra De ese hombre que dicen resulta significativo toda vez que, asumiéndose como final, propone el inicio de una lucha, una contienda que nace de la conciencia histórica de un repaso poético por el pasado prehispánico y colonial. Se retorna a estos tramos de la historia para hacernos ver a Cristóbal Colón pensando cómo convertir a los indios en fieles devotos del Señor; un volver al pasado histórico para observar a Felipe Guamán Poma de Ayala y al Inca Garcilaso de la Vega mientras uno dibuja las escenas de mal gobierno y el otro narra el ocaso de la dinastía inca. Se trata de una reescritura poética de la historia para extraer o producir una conclusión sobre la formación de las estructuras de dominación, incluso para explicar la formación de la sensibilidad de quienes se adhieren a los opresores y se distancian de los oprimidos (aunque sería lo mismo decir, quienes se afilian a los vencedores y se desafilian de los vencidos). El sujeto poético, tras esta revisión, se sitúa y nos permite reconocer su posición de descontento: "Cortaron la cabeza al Inca / (como todos los indios) / que nos maten ahora / mi Señor, mi Príncipe / valor grande Inca Túpac Amaru // iQué hemos hecho para quedar con los señores barbados / para no sentir el canto de la torcaza! Ya amanece" (p. 76, nuestras cursivas). 
¿A dónde quiere llegar el poeta con estas inserciones de la historia colonial? ¿Cómo comprender este proyecto poético que comenzó a ser visible con versos sobre las luchas sindicales y la importancia de la organización de los trabajadores para hacer respetar sus derechos? ¿Cómo entender este proyecto poético cuyos poemas le han cantado al amor y al desamor, tanto en los cuartos de hotel como bajo el destellar de coloridos paisajes? Visto en perspectiva y como conjunto, sin pretenderlo o fijándoselo como proyecto, el autor ha logrado componer un tratado poético sobre la formación de las estructuras sociales de dominación desde la Colonia hasta la actualidad, y, por defecto, sus poemas han propuesto también estrategias para hacerles frente. La diseminación de un utillaje conceptual proveniente del campo de la economía, la política y el activismo social así lo corroboran. De esta forma se advierte en sus textos iniciales de la década de los ochenta y noventa, cuando los nexos referenciales que establecen los poemas nos cuentan sobre la historia de la lucha social desde mediados del siglo $\mathrm{XX}$; $\mathrm{y}$, aunque en los primeros años del siglo XXI su poesía opta por cantar al amor, el desencuentro social, la dominación y la explotación se insinúan tras los abrazos que se reparten los amantes. Si seguimos la secuencia, comprenderemos que el proyecto poético pone en evidencia la continuidad de una estructura de dominación, y, por ende, la necesidad de una acción liberadora. La poesía de Gonzalo Espino ha sedimentado su experiencia del presente con elementos del pasado para que así el lector no pierda ni la memoria, ni la tradición, ni la conciencia crítica; y, sobre todo, para que no se olvide de que la poesía es más filosófica que la historia.

\section{Notas}

1 Para todos los casos, los versos provienen del libro que reúne los cuatro poemarios: Zafra (Trujillo: Papel de Viento, 2016).

\section{Javier Morales Mena}

Universidad Nacional Mayor de San Marcos; Lima, Perú

Contacto: jmoralesm@unmsm.edu.pe

https://orcid.org/0000-0002-7871-5685 